\title{
Behavior of singing fin whales Balaenoptera physalus tracked acoustically offshore of Southern California
}

\author{
Leah M. Varga*, Sean M. Wiggins, John A. Hildebrand \\ Scripps Institution of Oceanography, University of California San Diego, La Jolla, California 92093, USA
}

\begin{abstract}
Fin whales Balaenoptera physalus produce stereotyped low-frequency calls (15$30 \mathrm{~Hz}$ ) that can be detected at great ranges and are considered song when produced in a repeated temporal pattern. These calls, referred to as $20 \mathrm{~Hz}$ calls, were localized and tracked using a $1 \mathrm{~km}$ aperture array of 4 passive acoustic recorders at approximately $800 \mathrm{~m}$ depth northwest of San Clemente Island, offshore of Southern California, USA, for 4 continuous weeks during late fall 2007. A total of 1454 calls were localized over the recording period. The average $( \pm$ SD) estimated source sound pressure level was $194.8 \pm 0.2 \mathrm{~dB}_{\mathrm{pp}}$ re $1 \mu \mathrm{Pa}^{2}$ at $1 \mathrm{~m}$ (where pp is peak-to-peak) and $180.9 \pm 0.2 \mathrm{~dB}_{\mathrm{rms}}$ re $1 \mu \mathrm{Pa}$ at $1 \mathrm{~m}$ (where rms is root mean square). The majority of these calls were in the form of a doublet song pattern, with average inter-pulse intervals of 13 and $18 \mathrm{~s}$. These tracks are the first to be reported for transiting solitary singing fin whales using passive acoustic monitoring techniques. Acoustic tracking of fin whales provides insight into the ecology and behavior of this endangered species as well as vocal behaviors, which are important when studying the potential impact of anthropogenic noise. Call source sound pressure level, along with calling behavior, provides important parameters required for population density estimation. Furthermore, studying fin whale song patterns may aid in distinguishing different subpopulations.
\end{abstract}

KEY WORDS: Fin whales $\cdot$ Balaenoptera physalus $\cdot$ Tracking $\cdot$ Song $\cdot$ Passive acoustic monitoring

\section{INTRODUCTION}

Fin whales Balaenoptera physalus are found throughout the world's oceans and are listed as endangered under the US Endangered Species Act of 1973, following heavy exploitation and near extinction in the $20^{\text {th }}$ century by the modern whaling industry (Mizroch et al. 2009). Fin whales are known to produce a stereotyped high-amplitude and low-frequency call centered at $20 \mathrm{~Hz}$ (Watkins et al. 1987). These $20 \mathrm{~Hz}$ calls are produced as a pulse that lasts about $1 \mathrm{~s}$, are largely the same for different regions, and can be detected at long ranges (McDonald et al. 1995, Širović et al. 2007, 2013, Oleson et al. 2014). Fin whales mainly produce the $20 \mathrm{~Hz}$ pulse in 2 different

${ }^{*}$ Corresponding author: lvarga226@gmail.com forms: song and call-counter call (Watkins et al. 1987, McDonald et al. 1995, McDonald \& Fox 1999, Šrović et al. 2013, Buccowich 2014, Oleson et al. 2014). Song is a regular pattern of $20 \mathrm{~Hz}$ calls (Thompson et al. 1992, Delarue et al. 2013, Širović et al. 2013, 2017, Buccowich 2014, Oleson et al. 2014) and is associated with reproductive behaviors, as only males have been recorded producing it (Croll et al. 2002). An irregular pattern of $20 \mathrm{~Hz}$ pulses is described as call-counter call and is likely used more for general communication and as a way of maintaining contact between individuals (McDonald et al. 1995, McDonald \& Fox 1999, Širović et al. 2013). This irregular call-counter calling can be produced by 1 whale or multiple whales in an area.

() The authors 2018. Open Access under Creative Commons by Attribution Licence. Use, distribution and reproduction are unrestricted. Authors and original publication must be credited. 
Fin whale song is characterized as a patterned sequence of $20 \mathrm{~Hz}$ pulses, with repeating inter-pulse intervals (IPIs) of similar timing, and observed most commonly in the forms termed singlet or doublet (Watkins et al. 1987, Hatch \& Clark 2004, Oleson et al. 2014). A singlet song has 1 consistent IPI, while a doublet song has 2 different IPIs (Oleson et al. 2014). The IPI duration of fin whale song varies slightly across different geographic regions, indicating possible delineation in populations (Hatch \& Clark 2004, Delarue et al. 2009, Castellote et al. 2012, Oleson et al. 2014). These fin whale songs are typically comprised of calling sequences, followed by a silence that is associated with breathing gaps (Buccowich 2014). Fin whale song encounters vary in length, from 0.5 to $10 \mathrm{~h}$ (Hatch \& Clark 2004). Although the northeastern Pacific, including the waters offshore of Southern California, hosts fin whales year-round (Širović et al. 2013, Buccowich 2014), fin whale song most commonly occurs during the fall and winter months (Watkins et al. 2000, Oleson et al. 2014).

Since fin whale $20 \mathrm{~Hz}$ calls are stereotyped, high source level, and low frequency, they are ideal for passive acoustic monitoring (PAM) of seasonal and daily calling trends, characteristics and behaviors, and for tracking swimming behaviors. PAM advantages for studying marine mammals include the ability to collect long-term datasets in all weather conditions and oceans continuously, day and night, at relatively low cost (Mellinger et al. 2007). Furthermore, PAM is non-invasive and consequently has a minimal risk of impacting the behaviors of the whales, unlike other methods such as ship surveys and tagging (Moore \& Barlow 2011, Goldbogen et al. 2014). A limitation of using PAM devices is that they only record calling whales and therefore provide no information on silent whales (Mellinger et al. 2007, Širović \& Hildebrand 2011).

Using spatially fixed PAM devices to record sounds is a common and effective technique for tracking fin and other baleen whales (Zimmer 2011). For example, in the northeastern Pacific, kilometer-scale arrays of ocean bottom seismometers, which were designed to record low-frequency sounds $(<50 \mathrm{~Hz})$ from earthquakes, have been used to track fin whale $20 \mathrm{~Hz}$ pulses (McDonald et al. 1995, Wilcock 2012, Soule \& Wilcock 2013, Weirathmueller et al. 2013). Using underwater acoustics to track calling fin whales provides insight into their population size, structure, and distribution as well as their ecology and behaviors (McDonald \& Fox 1999). Using acoustics to study fin whale movements and vocal behaviors will aid in the understanding of how and to what extent fin whales typically use their vocal signals, and having a baseline of typical fin whale vocalizations will help in future studies assessing potential impacts of anthropogenic noise on this species (Croll et al. 2001, Henderson et al. 2014).

By using PAM techniques to estimate fin whale call source locations, their source sound pressure level (SPL) (i.e. source level) can be estimated. Call source level measurements, along with calling behavior, provide important parameters required for distance sampling population density estimation (Marques et al. 2009, Küsel et al. 2011, Hildebrand et al. 2015). In the northeastern Pacific, the source levels were calculated as $171 \mathrm{~dB}_{\mathrm{rms}}$ re $1 \mu \mathrm{Pa}$ at $1 \mathrm{~m}$ (Charif et al. 2002) and $189 \pm 5.8 \mathrm{~dB}_{\text {rms }}$ re $1 \mu \mathrm{Pa}$ at $1 \mathrm{~m}$ (Weirathmueller et al. 2013). These source levels were from call-counter calling behavior or were not assigned to either singing or call-counter calling behavior; to date, no source levels have been reported for calls categorized as song.

In this paper, we used an array of PAM devices to localize and track singing fin whales and to acoustically characterize their calls and behaviors off the coast of Southern California. We show examples of singing fin whale tracks as well as estimate various calling parameters, including source level and song pattern. The results provide insights into fin whale movement and calling behaviors within their Southern California habitat.

\section{MATERIALS AND METHODS}

\section{Study site and data collection}

Passive acoustic data were collected using a largeaperture array of high-frequency acoustic recording packages (HARPs, Wiggins \& Hildebrand 2007). Four HARPs were deployed to about $800 \mathrm{~m}$ depth in a square configuration $1 \mathrm{~km}$ per side off the northwestern shore of San Clemente Island in the Southern California Bight (Table 1, Fig. 1). The HARPs recorded for a continuous $4 \mathrm{wk}$ period, from 10 Novem-

Table 1. Instrument positions from acoustic-GPS localization ( $<5 \mathrm{~m}$ rms accuracy)

\begin{tabular}{|lccc|}
\hline & Latitude (N) & Longitude (W) & Depth (m) \\
\hline North & $33^{\circ} 12.182$ & $118^{\circ} 47.351$ & 853 \\
East & $33^{\circ} 11.649$ & $118^{\circ} 46.688$ & 837 \\
South & $33^{\circ} 11.102$ & $118^{\circ} 47.308$ & 788 \\
West & $33^{\circ} 11.627$ & $118^{\circ} 47.961$ & 846 \\
\hline
\end{tabular}




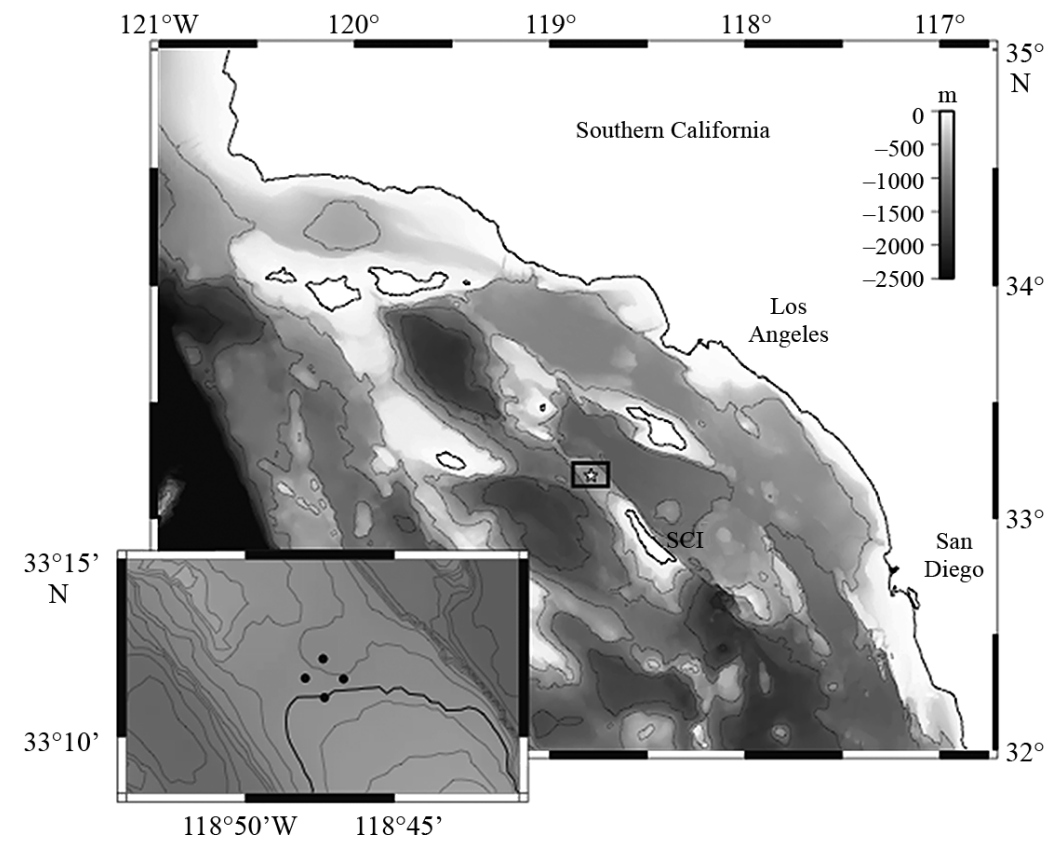

Fig. 1. Seafloor surrounding the study site (star) and inset map of the 4 high-frequency acoustic recording package instruments (circles). Large map contours are every $500 \mathrm{~m}$. Inset map contours are every $50 \mathrm{~m}$, with the thick contour line at $800 \mathrm{~m}$ and sloping shallower toward San Clemente Island (SCI) to the southeast

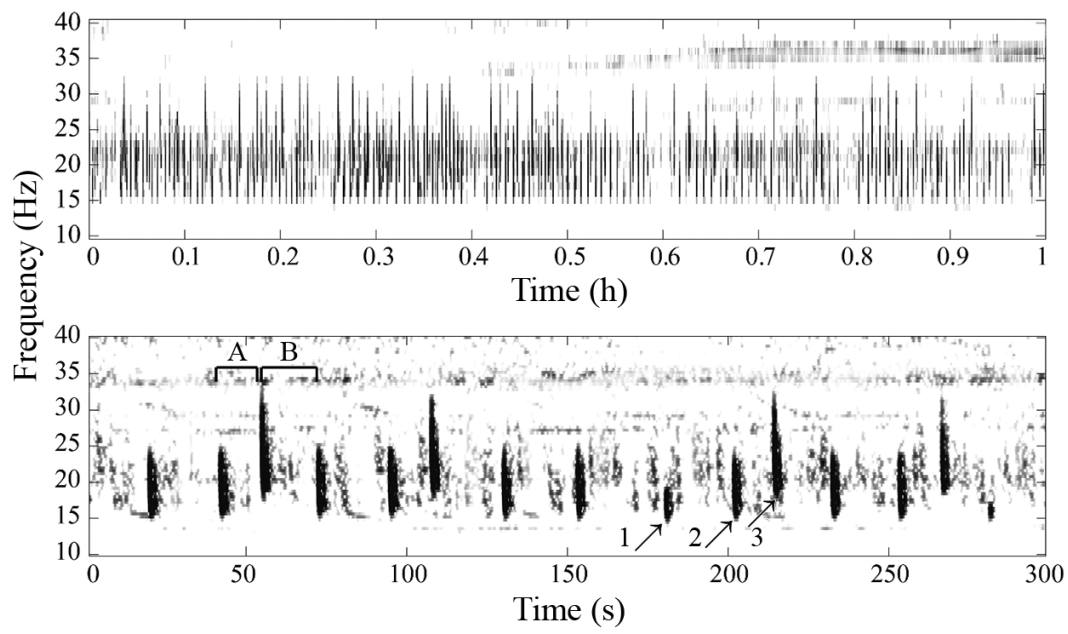

Fig. 2. One-hour long-term spectral average (top panel) of fin whale $20 \mathrm{~Hz}$ pulsed calls from high-frequency acoustic recording package south, recorded on 18 November 2007, starting at 00:30 h local time. Spectrograms (bottom panel) were calculated using the Welch (1967) method with $95 \%$ overlapping, 5000 point Hanning windows. Typical short (A) and long (B) inter-pulse intervals are indicated in the spectrogram as well as the 3 frequency call types: low (1), middle (2), and high (3)

ber to 7 December 2007. The hydrophones were suspended $\sim 10 \mathrm{~m}$ above the seafloor.

Localization of calling whales using an array requires precise estimates of the hydrophone sensor positions (Watkins \& Schevill 1972). The instrument depths and positions were estimated using a ship-based GPS and acoustic transponder survey from the deployment ship, the R/V 'Sproul', resulting in locations with uncertainties of less than about $5 \mathrm{~m}$ rms (Wiggins et al. 2013). The localization also requires clock synchrony between the instruments. HARPs have low clock drift rates, aiding in this synchronization, with drift rates in this study ranging from $-5.4 \times 10^{-8}$ to $1.2 \times 10^{-8}$ (Wiggins et al. 2013).

The HARP sample rate was continuous at $200 \mathrm{kHz}$, and the waveform recordings were decimated (low-pass filtered and resampled) by a factor of 100 , for an effective bandwidth of $10 \mathrm{~Hz}$ to $1 \mathrm{kHz}$, allowing for faster and more efficient analyses of low-frequency sounds. Long-term spectral averages (LTSAs, Fig. 2) were created using Triton, a custom-built software package for analyzing long-duration acoustic recordings (Wiggins \& Hildebrand 2007) and executed in the technical computing environment MATLAB (MathWorks). LTSAs provide additional efficiencies in analysis and are essentially long-duration spectrograms with sequential sound pressure spectrum levels (i.e. spectrum levels), calculated using the Welch (1967) method with $0 \%$ window overlap, Hanning windows, and $1 \mathrm{~Hz}$ frequency and $5 \mathrm{~s}$ time bins. To provide absolute received and estimated spectrum levels from the recordings, HARP hydrophones are calibrated at Scripps Institution of Oceanography and at the US Navy's Transducer Evaluation Center in San Diego, California, with response uncertainties of \pm 1 to $2 \mathrm{~dB}$.

\section{Call localization, source level estimate, and peak frequency}

To localize individual fin whale calls, the same $20 \mathrm{~Hz}$ pulse must have a high enough signal-to-noise ratio (SNR) to be detected on all recorders. Once detected, the time delay of the call between pairs of hydrophones is measured; there are 6 time delay hydrophone pairs for 4 hydrophones: $2-1,3-1,4-1,3-2,4-2$, and $4-3$. As a means of detecting and estimating time delays, 
waveform time series cross-correlation was performed between hydrophone recordings, and the time delays were taken as peak correlations above an empirically defined threshold using custom-built MATLAB software routines. This cross-site approach employed a Butterworth band-pass filter of 10 to $40 \mathrm{~Hz}$ to the waveform time series prior to crosscorrelation and stepped through the recordings using $2 \mathrm{~s}$ windows and with a $1 \mathrm{~s}$ step (overlap). The overlap minimized missed detections but resulted in duplicate detections, which were filtered out.

The measured time difference of arrivals (TDOAs) of fin whale calls from the cross-site cross-correlation method were used with a grid search minimization scheme to estimate the locations of calling whales. A constant whale source depth of $30 \mathrm{~m}$ (Goldbogen et al. 2014) was assumed, and using a $5 \times 5 \mathrm{~km}$ gridded model with $10 \mathrm{~m}$ resolution, TDOAs were calculated for the 6 near-seafloor hydrophone pairs. The calculated TDOAs were then differenced with the measured TDOAs to determine the least-squares best-fit location of the calling whale by selecting the grid point with the minimum total squared difference from the 6 pairs. The 3-dimension model space for the calculated TDOAs used a constant sound speed of $1490 \mathrm{~m} \mathrm{~s}^{-1}$, resulting in straight acoustic ray path propagation. The localization uncertainties were about $\pm 10 \mathrm{~m}$.

For $2 \mathrm{~s}$ windows with peak cross-correlation time lags above the threshold, call peak-to-peak SPL was measured from the window's corresponding waveform, and the call rms SPL was calculated using a time window that was $10 \mathrm{~dB}$ down from the peak cross-correlated value. The received peak-to-peak SPL (RL) was hydrophone calibration corrected and used for estimating the source level (SL) of the calls using the standard sonar equation: $\mathrm{SL}=\mathrm{RL}+\mathrm{TL}$, where TL is the transmission loss due to distance from the whale source to the hydrophone receiver. We assumed spherical spreading for TL because the array aperture and water depth were similar and therefore used $20 \times \log _{10}(R)$, with $R$ as slant range, in meters. The source-receiver ranges were calculated from the HARP positions and the estimated whale locations from the TDOA minimization method. The SL for each localized call was calculated in $\mathrm{dB}_{\mathrm{pp}}$ and $\mathrm{dB}_{\text {rms }}$ (where pp is peak-to-peak and rms is root mean square) for each instrument, resulting in 4 estimates of source level per metric.

Peak spectrum level frequencies were also measured for each cross-correlation detected call using the spectrum of the corresponding $2 \mathrm{~s}$ window. Peak spectrum level frequency of the calls varied, showing song characteristics with high-, middle-, and low-frequency bands described in 'Results' (Fig. 2, bottom panel).

The detections were filtered in a series of steps based on several parameters, allowing poor localizations and false detections to be removed from the results. The detected calls with slant ranges greater than $3 \mathrm{~km}$ and horizontal ranges greater than $2.1 \mathrm{~km}$ were filtered out because of the increased localization uncertainties at long ranges. A nearby anthropogenic noise source was detected by the crosscorrelation method and eliminated by an analyst (L.M.V.) in the localization step. Other detected calls from the cross-correlation were filtered out in the time delay step, where the TDOA values were not realistic based on the array geometry. Detected calls with an estimated duration of $<0.5$ or $>2$ s were eliminated, because these $20 \mathrm{~Hz}$ pulses are known to be $\sim 1 \mathrm{~s}$ (Watkins et al. 1987).

\section{Individual tracks}

Successive localizations of calling fin whales that were close in time and space form tracks. Four highSNR fin whale singing tracks were analyzed in greater detail for acoustic and swimming characteristics. The average swimming speed was calculated by dividing the distance traveled between consecutive call localizations and the time duration between those calls. The average call rate was calculated by dividing the number of detected calls by the time duration of the complete track. The average pp and rms source level, average call duration, and average peak spectrum level frequency were calculated using the cross-site correlation detector results, just as was calculated for the entire set of fin whale calls. Only high and middle peak frequency calls (Fig. 2, bottom panel) were used for the 4 tracks, as there were no detected low-frequency calls during these periods. The average IPIs of the tracks were calculated using the same analyst and detection method as for the song analyses described in the next subsection. The tracks selected for these analyses had a high SNR, lasted at least $30 \mathrm{~min}$, and had locations with low uncertainty, close to or within the instrument array.

In addition to the filtering steps described in the previous subsection that were performed on the entire dataset, these 4 individual tracks were filtered further; in the localization step, the locations of detected calls that were not realistic based on reasonable fin whale swimming speeds were removed by the analyst (L.M.V.). 


\section{Song analysis}

Since the automated cross-correlation detection method used a high threshold to avoid too many false detections, it missed some low-SNR calls, and some sections of data were manually logged by an analyst (L.M.V.) to quantify fin whale song IPI. One hour recordings were chosen randomly from each of the 26 full days of recording. The first and last days of recording, 10 November and 7 December 2007, were not included because these were less than full days. For each of the randomly chosen hours, fin whale song was logged using spectrograms in Triton. The data were viewed as $120 \mathrm{~s}$ segments for high temporal resolution, with spectrograms calculated using the Welch (1967) method, a 5000 point fast Fourier transform (FFT), 95\% temporal overlap with a Hanning window, and a Butterworth band-pass filter from 10 to $40 \mathrm{~Hz}$ applied to the waveform prior to the FFT. The Welch method was chosen because it reduces noise in the estimated power spectra in exchange for reducing the frequency resolution. The start times were logged by an analyst (L.M.V.) at the same time-frequency position on each call from the spectrogram window. When manually picking the onset of each $20 \mathrm{~Hz}$ pulse, the analyst error was $<0.10 \mathrm{~s}$. With these spectrogram parameters, the fin whale pulses were logged as song if they followed certain criteria: a temporal pattern of IPIs continued for a minimum of $2 \mathrm{~min}$ and the SNR of the calls was high enough that the pattern could be extracted by the analyst. The IPIs were calculated for each day's $1 \mathrm{~h}$ period, with doublet short and long IPIs averaged separately.

In some instances, there were distant, low received SPL background calls within the same time frame being analyzed for higher-level close calls. If the background call levels were low enough, then the closer targeted fin whale song still could be extracted and logged by the analyst. However, if the nearby fin whale song pattern was masked and could not be distinguished from the background calls, then the song was not logged. In the instances when the randomly chosen hour of data could not be logged due to lack of identifiable song, no song was logged from that day.

\section{RESULTS}

\section{Call localization, source level, and peak frequency}

A total of 1454 calls were localized using the $4 \mathrm{wk}$ recordings (Fig. 3). Although 4969 signals were detected during this time period, many of these did not

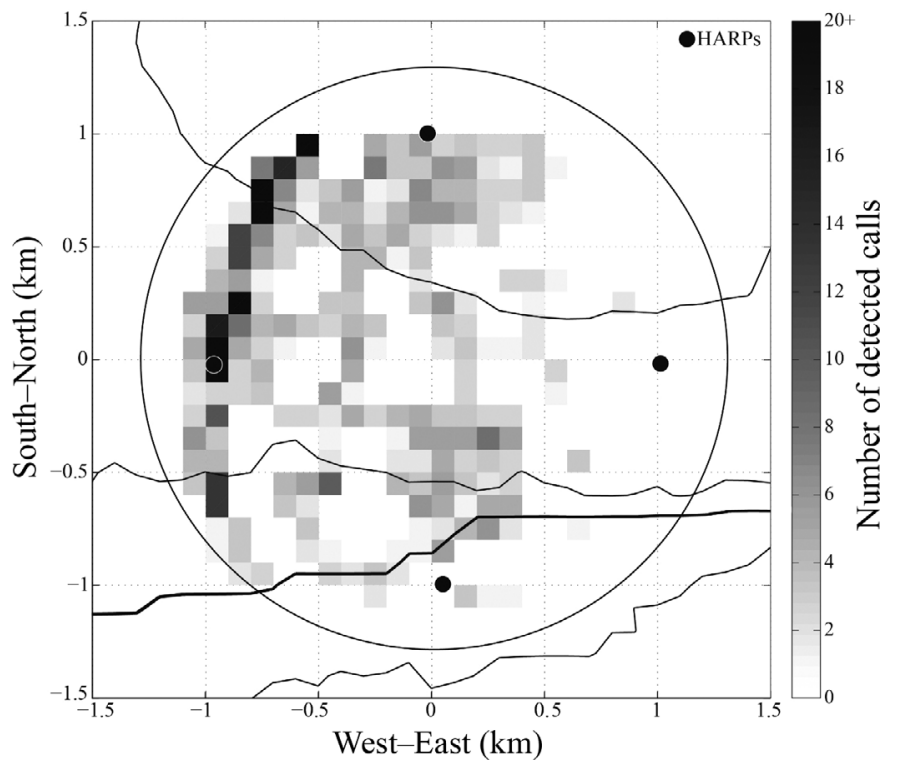

Fig. 3. Distribution of call locations $(\mathrm{n}=1454)$ in $100 \times 100 \mathrm{~m}$ bins over the recording period, with darker colors representing large numbers of calls per bin. Small black circles are high-frequency acoustic recording packages (HARPs). Large black circle (thin line) is the boundary used for localization; the detections localized within the boundary were kept, whereas those outside were not. Thick line is $800 \mathrm{~m}$ contour; thin lines are $25 \mathrm{~m}$ contours, becoming deeper to the north

pass the cross-correlation threshold and realistic localization filters. The majority of the detected and localized fin whale calls were located in the west-northwest region of the array, near the perimeter (Fig. 3). The average source levels of the filtered localized calls were $194.8 \pm 0.2 \mathrm{~dB}_{\mathrm{pp}}$ re $1 \mu \mathrm{Pa}^{2}$ at $1 \mathrm{~m}$, ranging from 182.1 to $217.4 \mathrm{~dB}_{\mathrm{pp}}$ re $1{\mu \mathrm{Pa}^{2}}^{2}$ at $1 \mathrm{~m}$ (Fig. 4), and $180.9 \pm 0.2 \mathrm{~dB}_{\text {rms }}$ re $1 \mu \mathrm{Pa}$ at $1 \mathrm{~m}$, ranging from 166.2 to $205.9 \mathrm{~dB}_{\mathrm{rms}}$ (Fig. 5). The average duration of the 1454 localized $20 \mathrm{~Hz}$ calls was $1.2 \pm 0.1 \mathrm{~s}$. Our results are reported $\pm \mathrm{SD}$.

The average peak spectrum level frequency of all the localized calls was $22.4 \pm 0.1 \mathrm{~Hz}$ (Fig. 6). There were 3 distinct call types within these data, separated by frequency and bandwidth (Fig. 2, bottom panel). The highest-frequency call type had an average peak frequency of $23.3 \pm 0.1 \mathrm{~Hz}$ and had the largest bandwidth, spanning $\sim 13$ to $15 \mathrm{~Hz}$. The middlefrequency call type had an average peak frequency of $19.0 \pm 0.1 \mathrm{~Hz}$ and a bandwidth of $\sim 10 \mathrm{~Hz}$. The lowfrequency call type, which was not nearly as common and tended to occur at the beginning or end of calling sequences (i.e. just before or just after a breathing gap), had an average peak frequency of $16.6 \pm 0.2 \mathrm{~Hz}$ and a narrow bandwidth of $\sim 5 \mathrm{~Hz}$. Of the total 1454 detected $20 \mathrm{~Hz}$ calls, 1147 (79\%) were the highfrequency call type, 298 (20\%) were the middle call 
type, and $9(1 \%)$ were low. The cross-site crosscorrelation method missed some of the lower-frequency call type, because of low SNR. The overall

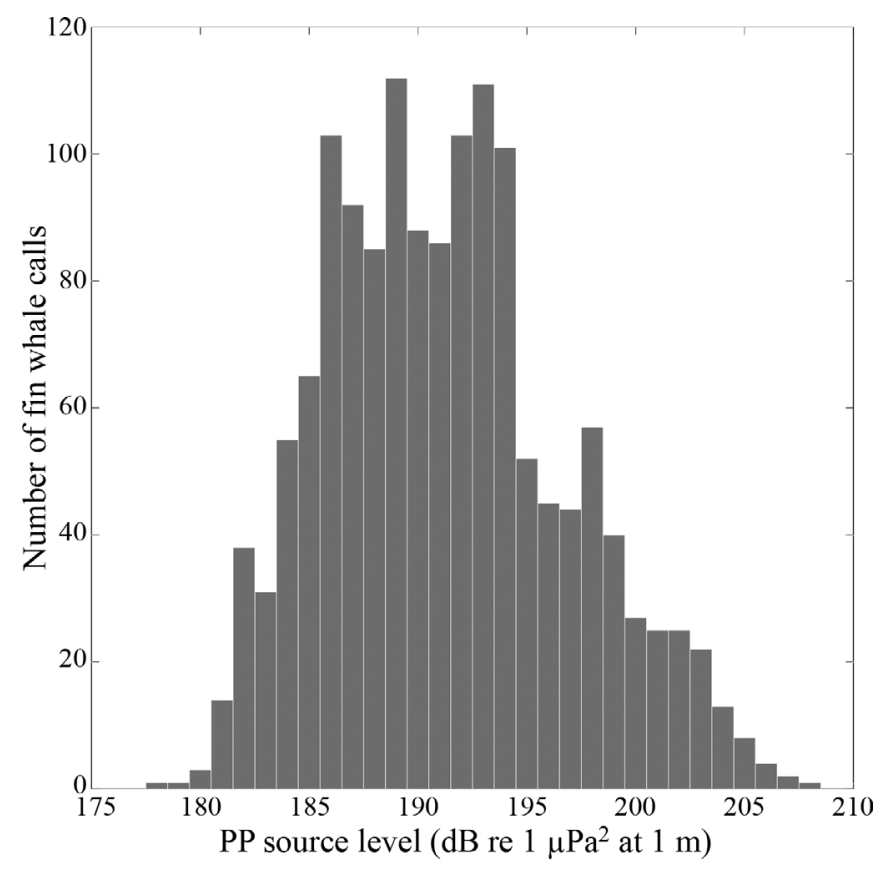

Fig. 4. Distribution of peak-to-peak (pp) call source levels $(\mathrm{n}=1454)$, with a mean of $194.8 \pm 0.2 \mathrm{~dB}$ re $1 \mu \mathrm{Pa}^{2}$ at $1 \mathrm{~m}$. Each call source level is averaged using all 4 instrument estimates

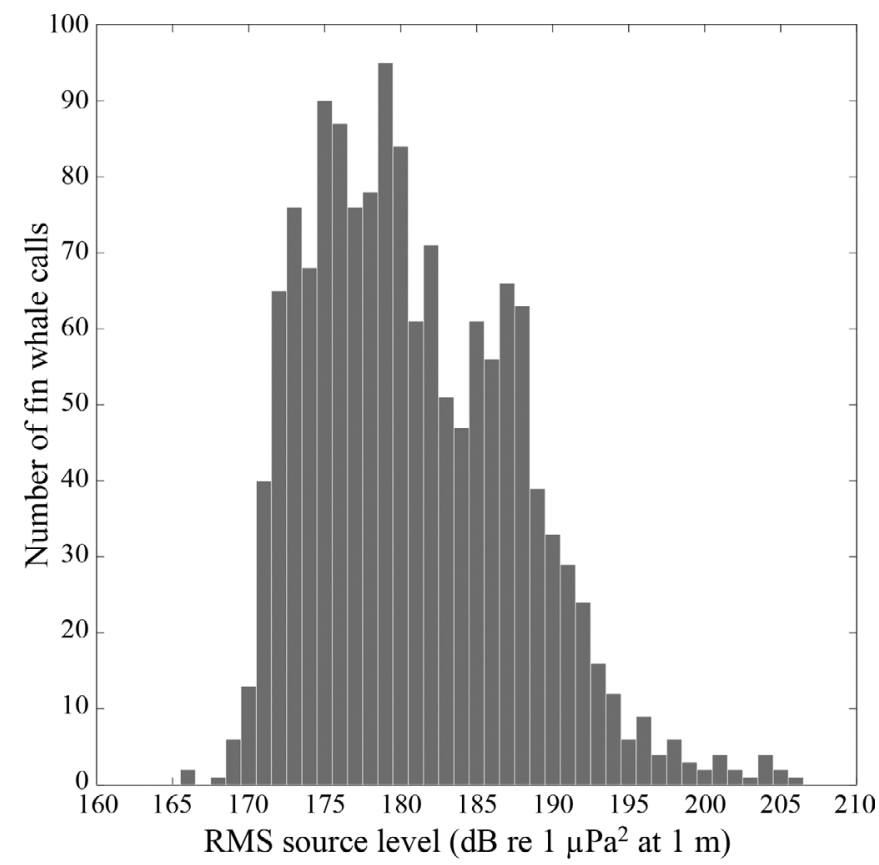

Fig. 5. Distribution of rms call source levels $(n=1454)$, with a mean of $180.9 \pm 0.2 \mathrm{~dB}$ re $1 \mu \mathrm{Pa}$ at $1 \mathrm{~m}$. Each call source level is averaged using all 4 instrument estimates detected call count is an underestimate of the total number of fin whale calls recorded because of the missed low-SNR calls.

\section{Four individual tracks}

Four high-resolution tracks of individual singing fin whales were analyzed, all about an hour or less from start to finish, and the number of calls localized in each track ranged from 64 to 135 (Table 2, Fig. 7). The average speeds from the 4 detailed tracks ranged from 5.3 to $8.8 \mathrm{~km} \mathrm{~h}^{-1}$, with a median of $7.1 \mathrm{~km} \mathrm{~h}^{-1}$. The average call peak-to-peak source level for the 4 tracks was $198.3 \mathrm{~dB}_{\mathrm{pp}}$ re $1 \mathrm{\mu Pa}^{2}$ at $1 \mathrm{~m}$, ranging from 193.0 to $201.1 \mathrm{~dB}_{\mathrm{pp}}$ re $1 \mathrm{\mu Pa}^{2}$ at $1 \mathrm{~m}$. The rms source level values ranged from 178.6 to $189.3 \mathrm{~dB}_{\text {rms }}$ re $1 \mu \mathrm{Pa}$ at $1 \mathrm{~m}$, with a mean value of $185.8 \mathrm{~dB}_{\mathrm{rms}}$ re $1 \mu \mathrm{Pa}$ at $1 \mathrm{~m}$. Both the peak-to-peak and rms source level averages for the 4 tracks were higher than the respective averages for the entire dataset because only highSNR tracks were used. The call durations from these 4 tracks ranged from 0.9 to $1.3 \mathrm{~s}$. The average high peak frequency was $23.3 \mathrm{~Hz}$, and the average middle peak frequency was $18.9 \mathrm{~Hz}$ for all 4 tracks. The mean call rate was 1.9 calls $\mathrm{min}^{-1}$, with a range of 1.4 to 2.3 calls $\mathrm{min}^{-1}$. The song pattern from these 4 tracks was similar to the song pattern of the rest of the recordings, with an average short IPI of $12.6 \mathrm{~s}$, rang-

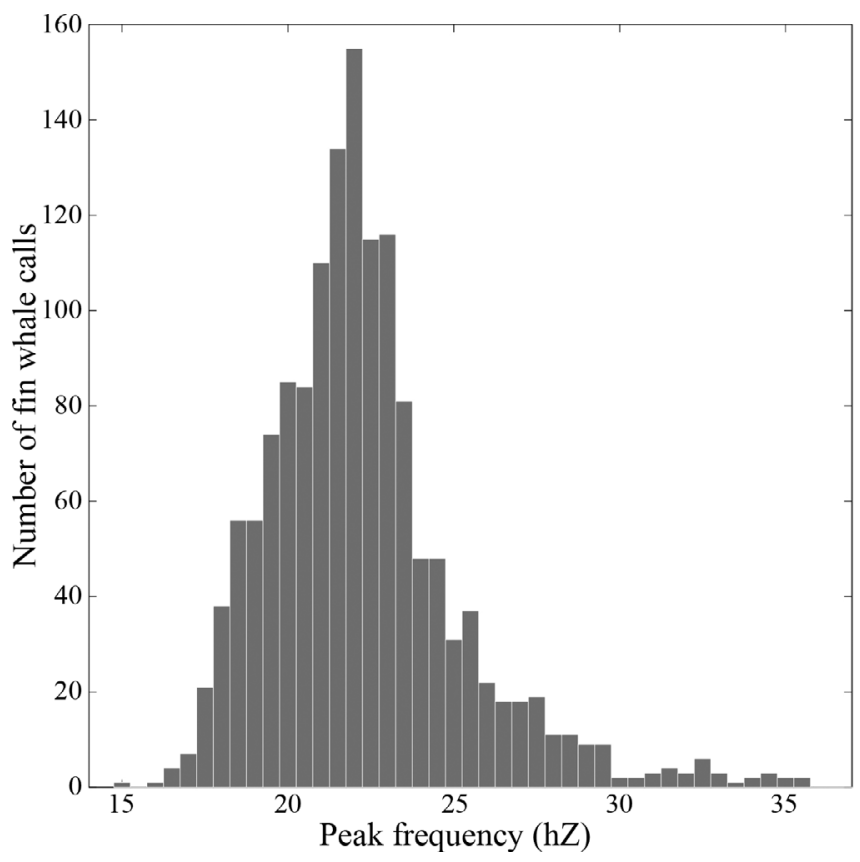

Fig. 6. Distribution of call peak spectrum level frequencies, with a mean of $22.4 \pm 0.1 \mathrm{~Hz}$. Each call peak frequency is averaged using all 4 instrument estimates 
Table 2. Characteristics of 4 individual fin whale singing tracks recorded in 2007: date, duration of track, number of calls, mean swimming speed, mean peak-to-peak source level (SL), mean rms SL, mean duration, mean high and mean middle peak frequencies, call rate, and mean short and long inter-pulse intervals (IPIs). See Fig. 7 for tracks and call locations. Mean values presented as mean $\pm \mathrm{SD}$

\begin{tabular}{|c|c|c|c|c|}
\hline & Track A & Track B & Track C & Track D \\
\hline Date & $18 \mathrm{Nov}$ & $23 \mathrm{Nov}$ & $29 \mathrm{Nov}$ & $3 \mathrm{Dec}$ \\
\hline Track duration (min) & 62 & 41 & 55 & 54 \\
\hline No. of calls & 135 & 64 & 66 & 77 \\
\hline Mean speed $\left(\mathrm{km} \mathrm{h}^{-1}\right)$ & $5.3 \pm 0.3$ & $8.3 \pm 0.8$ & $8.8 \pm 0.8$ & $5.9 \pm 0.6$ \\
\hline Mean peak-to-peak $\mathrm{SL}\left(\mathrm{dB}_{\mathrm{pp}}\right.$ re $1 \mu \mathrm{Pa}^{2}$ at $\left.1 \mathrm{~m}\right)$ & $201.1 \pm 2.4$ & $198.4 \pm 3.8$ & $200.8 \pm 5.0$ & $193.0 \pm 1.7$ \\
\hline Mean rms SL ( $\mathrm{dB}_{\mathrm{rms}}$ re $1 \mu \mathrm{Pa}$ at $\left.1 \mathrm{~m}\right)$ & $187.8 \pm 0.3$ & $187.6 \pm 0.9$ & $189.3 \pm 0.7$ & $178.6 \pm 0.3$ \\
\hline Mean duration (s) & $0.9+0.1$ & $1.2+0.1$ & $1.0+0.1$ & $1.3 \pm 0.1$ \\
\hline Mean high peak frequency $(\mathrm{Hz})$ & $22.7 \pm 0.2$ & $24.0 \pm 0.3$ & $22.7 \pm 0.3$ & $23.9 \pm 0.3$ \\
\hline Mean middle peak frequency (Hz) & $18.8 \pm 0.1$ & $19.0 \pm 0.1$ & $18.8 \pm 0.2$ & $18.9 \pm 0.1$ \\
\hline Call rate $\left(\right.$ calls $\mathrm{min}^{-1}$ ) & 2.3 & 2.2 & 1.6 & 1.4 \\
\hline Mean short IPI (s) & $12.8 \pm 0.1$ & $12.7 \pm 0.2$ & $12.9 \pm 0.1$ & $12.0 \pm 0.1$ \\
\hline Mean long IPI (s) & $19.5 \pm 0.2$ & $18.1 \pm 0.4$ & $18.1 \pm 0.3$ & $18.0 \pm 0.2$ \\
\hline
\end{tabular}

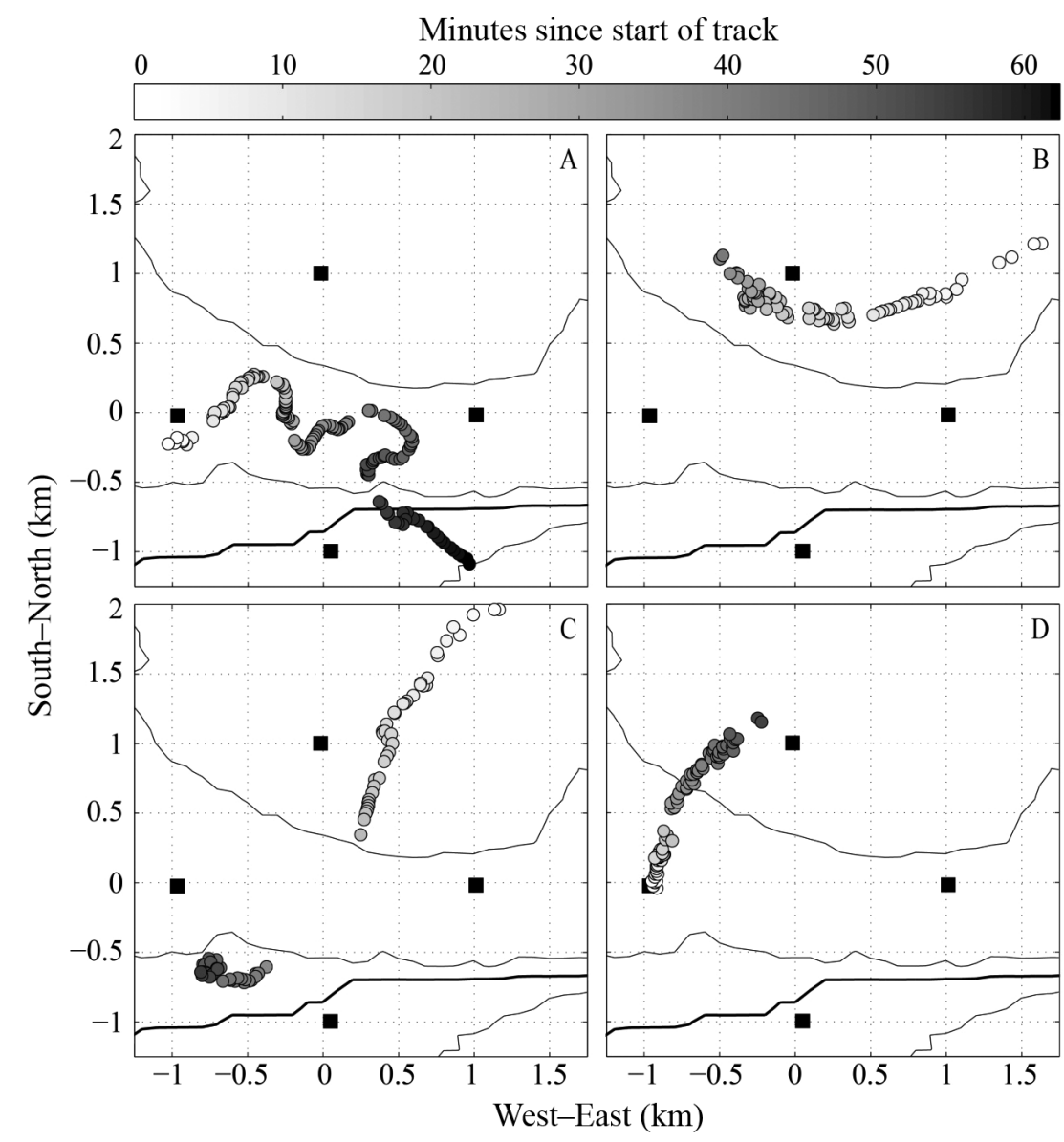

Fig. 7. Four individual singing fin whale tracks with call locations shown as circles and darker gray shading representing later time along the track. (A) Track A on 18 November 2007, lasting from 23:51 to 00:53 h local time. (B) Track B on 23 November 2007, lasting from 19:44 to 20:25 h local time. (C) Track C on 29 November 2007, lasting from 08:45 to 09:40 h local time. (D) Track D on 3 December 2007, lasting from 23:07 to 00:01 h local time. Gray scale on top is relative track timing, in minutes from start time. Thick line is $800 \mathrm{~m}$ contour; thin lines are $25 \mathrm{~m}$ contours, becoming deeper to the north. Black squares are highfrequency acoustic recording packages ing from 12.0 to $12.9 \mathrm{~s}$, and an average long IPI of $18.4 \mathrm{~s}$, ranging from 18.0 to $19.5 \mathrm{~s}$.

Tracks B (heading west-northwest) and $\mathrm{D}$ (heading northeast) and the first section of Track C (heading southwest) show distinct, but slightly curvilinear, directions of travel; Track A (heading southeast) is much more indirect and serpentine (Fig. 7). The whales in Tracks $\mathrm{B}$ and $\mathrm{C}$ are swimming faster $\left(\sim 8 \mathrm{~km} \mathrm{~h}^{-1}\right)$ than the whales in Tracks A and $\mathrm{D}\left(\sim 5 \mathrm{~km} \mathrm{~h}^{-1}\right)$. The breaks shown in the tracks separate the calling sequences and are likely breathing gaps, suggesting the whale stopped singing to surface, breathe, and descend before continuing to sing. These breaks are most apparent in Track A (Fig. 7).

\section{Song}

Of the $26 \mathrm{~h}$ of analyst-evaluated recordings, $22 \mathrm{~h}$ had clear and identifiable fin whale song. A total of 1449 calls were analyst logged as fin whale song, and all were classified as doublet song. The average short IPI of the doublet song was $12.9 \pm 0.1 \mathrm{~s}$, and the average long IPI was $18.4 \pm 0.1 \mathrm{~s}$ (Fig. 8). The short IPI was more common than the long IPI. There was also a common frequency component with the doublet IPI pattern. The short IPI 


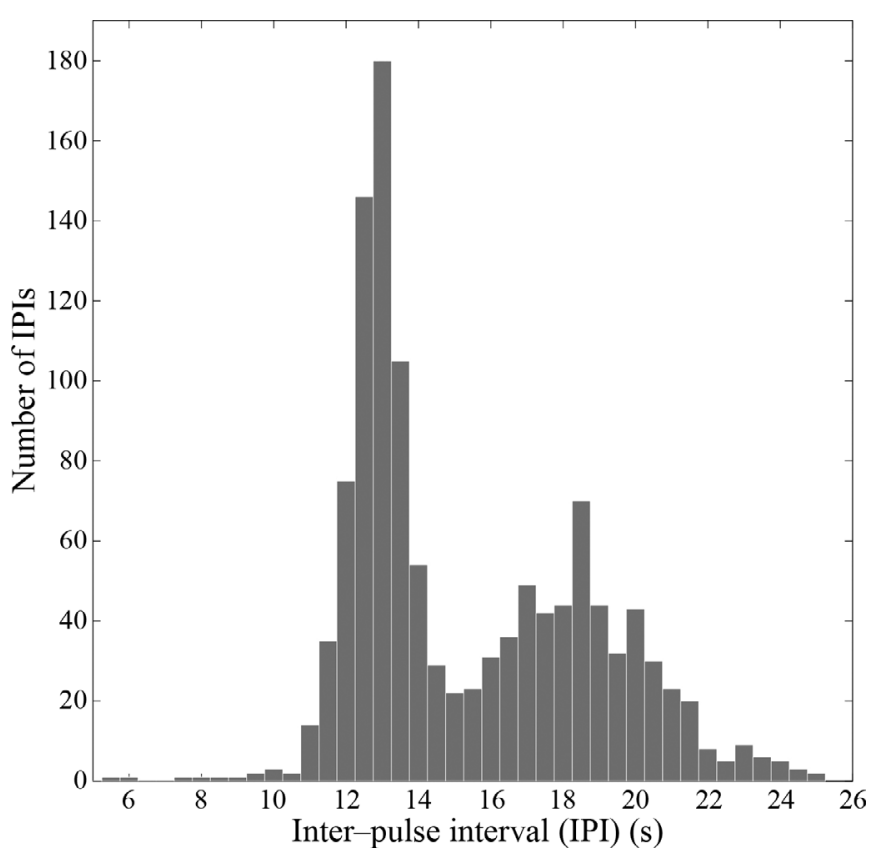

Fig. 8. Inter-pulse intervals (IPIs) for all analyst-evaluated song. The bimodality indicates a clear 13 and $18 \mathrm{~s}$ doublet song pattern

( 13 s) typically followed the middle-frequency call type ( 19 Hz), whereas the long IPI ( 18 s) typically followed the high-frequency call type $(\sim 23 \mathrm{~Hz})$ (Fig. 2, bottom panel).

The remaining $4 \mathrm{~h}$ that did not have clear and identifiable fin whale song were not logged for 2 reasons: 3 of those $4 \mathrm{~h}$ had overlapping songs from 2 or more fin whales that were indistinguishable, and the fourth hour of data had high-amplitude, low-frequency noise, masking the $20 \mathrm{~Hz}$ calls.

\section{DISCUSSION}

The tracks presented here are of individual singing fin whales using PAM techniques with whale positions at much higher resolution than previous studies. Fin whales have been effectively tracked in the past, but the calls were not categorized or were categorized as call-counter call, not song, and used arrays with much larger aperture, often tracking multiple animals over tens of kilometers (Watkins et al. 1987, McDonald et al. 1995, Wilcock 2012, Soule \& Wilcock 2013, Weirathmueller et al. 2013). We surmise that our 4 tracks are single animals singing, based on a lack of competing background calls, a consistent pattern of IPIs, and a smooth and tightly spaced track with reasonable swim speeds. Although it is possible that more than 1 whale participated in making each song track, we believe these tracks are of individual singing whales. There is also the possibility that 2 or more whales are transiting together, but only one is singing.

The effects of anthropogenic noise on cetaceans are a major concern (Croll et al. 2001, Melcón et al. 2012, Henderson et al. 2014), and the results presented here further build the baseline understanding of fin whale movements and vocal behaviors needed to evaluate how man-made sound may affect this species.

\section{Call localization, source level, and peak frequency}

The localized fin whale calls from these recordings were not uniformly distributed throughout our detection range within the array of instruments. The distribution indicates a preferred singing area in the westnorthwest region of the array (Fig. 3). The whales may have been more uniformly distributed during our recording period but were silent and therefore not monitored by our method. The arc of increased detections along the northwest side of the array (Fig. 3) mirrors the bathymetric contours of the ocean floor to the northwest of San Clemente Island as well as the island's coastline (Fig. 1); these physical features may impact the oceanographic conditions, which subsequently may influence the preferred areas used by these traveling and singing fin whales.

Fin whale call rms source levels in this study were within the range of previously reported source level values for this species in the northeastern Pacific. Having a good estimate of fin whale source levels provides one of the key parameters for estimating the probability of detection of these animals, which is important for estimating population densities, and potentially their susceptibility to the impacts from anthropogenic noise sources.

The variance in our source level estimates may be due to sound propagation variability in the water column and to reflections at the sea surface and seafloor, which are likely to cause received level variation from waveform destructive and constructive interference. The variability also could be caused by uncertainties in the horizontal and vertical location of the source. And while low-frequency calls emitted by baleen whales are typically considered to be omnidirectional (Mellinger et al. 2007), there is evidence that some baleen whale calls, namely those produced by bowhead whales, are directional (Blackwell et al. 2012). Therefore, there may also be directionality or beam pattern associated with fin whale calls such that focusing or attenuation from the source-generating 
structure through different parts of the animal would result in different source level estimates from a whale with different headings compared to the receiver. Another potential source of variability in the measured levels is the ability for individuals to vary their source levels. Individual dolphins in the wild have been shown to vary their whistle source levels (Janik 2000), and thus by reasonable extension, baleen whales may vary their call source levels depending on individual behavior or morphology.

In future studies aiming to track calling baleen whales, we suggest using nested arrays, with small $\sim 1 \mathrm{~km}$ aperture arrays of hydrophones spaced 5 to $10 \mathrm{~km}$ apart from other small-aperture arrays. For example, fin whale $20 \mathrm{~Hz}$ calls propagate at great ranges (Watkins et al. 1987, McDonald et al. 1995, Širović et al. 2007) such that a large array composed of nested smaller arrays allows for coarse tracking of fin whales over long periods and large distances while also being able to provide high-resolution track detail using the nested small-aperture arrays.

\section{Individual tracks}

The 4 detailed tracks show variability in the movements of individual singing fin whales. These swimming speeds $\left(5-8 \mathrm{~km} \mathrm{~h}^{-1}\right)$ are within the range of previously reported fin whale swimming speeds. For example, in the northeastern Pacific, fin whale tracks from presumably call-counter calling whales show average swimming speeds ranging from 5 to $14 \mathrm{~km} \mathrm{~h}^{-1}$ (McDonald et al. 1995). In 2 other studies where the calling behaviors were not categorized, fin whale swim speeds were approximately $8 \mathrm{~km} \mathrm{~h}^{-1}$ (Wilcock 2012) and ranged from 1 to $12 \mathrm{~km} \mathrm{~h}^{-1}$, with a mean of $4.3 \mathrm{~km} \mathrm{~h}^{-1}$ (Soule \& Wilcock 2013).

While fin whale swimming speeds during singing were similar between tracks, the direction of travel showed no preferred heading. Two of the tracks, as well as the first half of a third track, were similar in their large curved routes, but 1 track showed a very different behavior with many small radius turns over the $1 \mathrm{~h}$ route. Another behavior unique to just one of the 4 singing tracks showed an almost 15 min pause in calling, with about $1 \mathrm{~km}$ travel before the whale resumed its singing, but swimming in a smaller area and not traveling very far (Track C). We suggest this track is most likely the same whale singing before and after the long pause because the direction of travel is the same, the call levels are similarly high, and there is only 1 song sequence in the recording during this period; however, since there was no infor- mation on the whale's position when it was not calling, it is possible that the first part of this track was from one whale and the second part from another. Future studies with GPS or satellite-tagged whales would provide insight into the general swimming behavior when not calling. The variability in the directionality of these tracks could be attributed to behavioral preference of individual singing males; song holds a reproductive purpose for this species, and individual males may have varying singing behaviors and swimming behaviors when looking for a mate.

The whales from these tracks were singing very similar songs, all with the 13/18 s doublet pattern. However, there is variability in the call rates between the 4 tracks, ranging from 1.4 to 2.3 calls $\mathrm{min}^{-1}$. This variability may be due to the differences in the number and length of breathing gaps. These breathing gaps or pauses in the singing were included in our call rate calculations, thereby potentially lowering short-term call rate estimates. Another source of variability may be the whale's occasional omission of $20 \mathrm{~Hz}$ calls within the song. These omissions changed the IPI of the tracks and subsequently the call rate.

The range in the call duration estimates for the tracks $(0.9-1.3 \mathrm{~s})$ may be due to the multiple path arrivals of the signals. The duration values for the 4 tracks are relatively close to the average duration value for the entire dataset $(1.2 \mathrm{~s})$.

\section{Location uncertainty}

Low call location uncertainty is important for estimating source level metrics and for studying detailed movement behavior. A whale calling within or near the boundaries of an array can be localized with lower position uncertainty than whales outside of an array, and this was the primary reason we discarded localized calls based on range. Also, low-SNR calls were not used because their low quality resulted in locations with high uncertainties, as was the case with the low-frequency calls.

Source level estimates showed variability that may be attributed to individual fin whale morphology and behaviors. Also, some of this variability may be caused by location uncertainty; however, the smoothness in the detailed tracks suggests low location error, and it is more likely that propagation effects such as constructive/destructive interference were the cause of any source level estimate error.

While the sample size in this study is smaller compared to other fin whale call studies which have longer time series and larger arrays (McDonald et al. 
1995, Wilcock 2012, Soule \& Wilcock 2013, Weirathmueller et al. 2013), this study provided much higher whale position and track resolution, the ability to track individual calling whales to evaluate unique calling and swimming behaviors, and precise timing of the patterned IPIs for song analysis, thus distinguishing these tracks as song, not call-counter call.

\section{Song}

Off the coast of Southern California, fin whale song doublet IPI has been shown to increase over the $4 \mathrm{yr}$ recording period from 2008 to 2012, with the short IPI starting at $12.0 \pm 1.2 \mathrm{~s}$ and ending at $17.7 \pm 0.6 \mathrm{~s}$, and the long IPI starting at $17.6 \pm 1.6 \mathrm{~s}$ and ending at 23.2 $\pm 2.6 \mathrm{~s}$ (Buccowich 2014), in agreement with the doublet IPI (13/18 s) from our recordings (2007). On the other hand, the 13/18 s doublet song from our study is overall shorter than an earlier study (2000-2003) in this region, where doublet songs ranged from $\sim 18 / 24$ to $\sim 27 / 33 \mathrm{~s}$, with the IPIs increasing throughout each calling season and then resetting at the beginning of the following season (Oleson et al. 2014).

Although our 13/18 s doublet pattern was consistent and ubiquitous throughout the recordings, there were occasional variations in the song. For example, a singing whale sometimes skipped 1 call, for instance a high-frequency call type, before returning to the 13/18 s doublet pattern.

In fin whale tracking studies using larger-aperture arrays than ours, the singing behavior may be misidentified as call-counter call (McDonald et al. 1995, Soule \& Wilcock 2013). It was hypothesized in one of these studies that a 24/13 s IPI calling pattern recorded in the northeastern Pacific was more likely to be from 2 whales calling at 2 different frequencies rather than 1 individual singing whale (Soule \& Wilcock 2013). The spatial uncertainty in that study was $0.5 \mathrm{~km}$ for calling whales within the array of recorders and increased to several kilometers the farther a calling whale was from the array. Because of this spatial uncertainty, the authors were not able to resolve the 2 different frequency call types into separate tracks. However, if the 2 frequency call types differ in physical position within the array as well as in source levels, then that would support the authors' hypothesis that the 24/13 s calling pattern was produced by 2 calling whales, one singing at a higher frequency and one at a lower frequency. But if the tracks and amplitudes cannot be distinguished, then this calling pattern likely would be attributed to 1 singing fin whale, like that found in our study. A closer look at the track positions and the source levels from the 24/13 s IPI sequences may provide insight on this hypothesis, but high position uncertainty from large sensor spacing may preclude this.

In another large-aperture array study, fin whales were tracked and considered call-counter calling; again, this may be an example of fin whales singing. Three fin whales transiting together, from 1 sequence of $20 \mathrm{~Hz}$ calls lasting about $8 \mathrm{~h}$ in late August 1990, were reported as call-counter calling (McDonald et al. 1995). Just as in our study, the source location could be adequately estimated when the whale was close to or within the boundaries of the array. When the calling whale was beyond $10 \mathrm{~km}$ from the array of instruments, the bearing estimation from the array to the call was precise, but the estimated location and range uncertainty increased. In the McDonald (1995) study, a sequence of $20 \mathrm{~Hz}$ calls was localized, and it was concluded that 3 individuals were calling, several kilometers apart from one another. However, from the time series and corresponding spectrogram of the 3 calls associated with the 3 whales $(a, b$, and c), there were most likely 2 individuals transiting in a coordinated way, where one was singing and the other was silent. The calls reported as whales a and $b$, when analyzed together, were likely from 1 whale's doublet song, with a short IPI of $\sim 13 \mathrm{~s}$ and a long IPI of $\sim 19 \mathrm{~s}$, which is similar to the $13 / 18 \mathrm{~s}$ doublet song from our results as well as from the Buccowich (2014) study. This summation is based on the short spectrogram and time series in the paper, but additional analysis of longer sequences of $20 \mathrm{~Hz}$ calls from that dataset could provide more detail on fin whale calling behavior.

Fin whale song has been used as an indicator of population dynamics, and recorded differences in song parameters and characteristics, such as the 3 different frequency call types and how the call types are used in conjunction with the IPIs, have identified several potentially distinct fin whale populations (Hatch \& Clark 2004, Oleson et al. 2014). These distinctions may lead to more effective management practices in the future, catered to the needs of the differing subpopulations.

\section{CONCLUSIONS}

Using spatially fixed PAM devices to track calling whales is a key technique for monitoring and assessing the movement and calling behaviors of these animals. Large-aperture arrays provide for large spatial and long temporal monitoring of calling whales, but 
well-designed small-aperture arrays can provide higher spatial resolution, allowing for more detailed investigations of swimming and call behavior such as song. Tracking calling whales, distinguishing song from call-counter call, and studying fin whale song temporal patterns are important for understanding calling behaviors and habitat use. Fin whale call source level estimates aid in determining the detection range and therefore, through distance sampling, population density estimates for the species. Quantifying fin whale song in different regions will help efforts to distinguish populations, potentially leading to future management practices.

The tracks presented here are the first reported examples of singing fin whales transiting alone using PAM. The song pattern, with a 13/18 s doublet IPI, matches well other song patterns studied in the northeastern Pacific. The source level estimates are similar to previously reported source levels for fin whales around the world and in the northeastern Pacific. The localizations are highly detailed and provide insight into the movements and behaviors of singing fin whales offshore of Southern California.

Acknowledgements. The authors thank Ana Širović, Gerald D'Spain, and Ally Rice for their comments that helped strengthen the manuscript. The research presented was possible due to funding provided by the Chief of Naval Operations N45 and the Naval Postgraduate School, thanks to Frank Stone, Ernie Young, Curt Collins, and John Joseph, and from the Pacific Fleet, thanks to Chip Johnson. Thanks to Bill Gaines, the crew of the R/P 'FLIP', and the captain and crew of the R/V 'Sproul'. The authors also thank the technicians and data analysts of the Scripps Whale Acoustics Lab at Scripps Institution of Oceanography.

\section{LITERATURE CITED}

Blackwell SB, McDonald TL, Kim KH, Aerts LAM, Richardson WJ, Greene JCR, Streever B (2012) Directionality of bowhead whale calls measured with multiple sensors. Mar Mamm Sci 28:200-212

Buccowich J (2014) Fin whale song variability in the Southern California Bight, from 2008 through 2012. MSc thesis, University of California, San Diego, CA

Castellote M, Clark CW, Lammers MO (2012) Fin whale (Balaenoptera physalus) population identity in the western Mediterranean Sea. Mar Mamm Sci 28:325-344

* Charif RA, Mellinger DK, Dunsmore KJ, Fristrup KM, Clark CW (2002) Estimated source levels of fin whale (Balaenoptera physalus) vocalizations: adjustments for surface interference. Mar Mamm Sci 18:81-98

Croll DA, Clark CW, Calambokidis J, Ellison WT, Tershy BR (2001) Effect of anthropogenic low-frequency noise on the foraging ecology of Balaenoptera whales. Anim Conserv 4:13-27

Croll DA, Clark CW, Acevedo A, Tershy B, Flores S, Gedamke J, Urban J (2002) Bioacoustics: only male fin whales sing loud songs. Nature 417:809
Delarue J, Todd SK, Van Parijs SM, Di Iorio L (2009) Geographic variation in Northwest Atlantic fin whale (Balaenoptera physalus) song: implications for stock structure assessment. J Acoust Soc Am 125:1774-1782

* Delarue J, Martin B, Hannay D, Berchok CL (2013) Acoustic occurrence and affiliation of fin whales detected in the northeastern Chukchi Sea, July to October 2007-10. Arctic 66:159-172

* Goldbogen JA, Stimpert AK, DeRuiter SL, Calambokidis J and others (2014) Using accelerometers to determine the calling behavior of tagged baleen whales. J Exp Biol 217: 2449-2455

Hatch LT, Clark CW (2004) Acoustic differentiation between fin whales in both the North Atlantic and North Pacific oceans, and integration with genetic estimate of divergence. Working paper SC/56/SD8, International Whaling Commission, Cambridge

*Henderson EE, Smith MH, Gassmann M, Wiggins SM, Douglas AB, Hildebrand JA (2014) Delphinid behavioral responses to incidental mid-frequency active sonar. J Acoust Soc Am 136:2003-2014

Fildebrand JA, Baumann-Pickering S, Frasier KE, Trickey JS and others (2015) Passive acoustic monitoring of beaked whale densities in the Gulf of Mexico. Sci Rep 5:16343

Janik VM (2000) Source levels and the estimated active space of bottlenose dolphin (Tursiops truncatus) whistles in the Moray Firth, Scotland. J Comp Physiol A 186: 673-680

Küsel ET, Mellinger DK, Thomas L, Marques TA, Moretti D, Ward J (2011) Cetacean population density estimation from single fixed sensors using passive acoustics. J Acoust Soc Am 129:3610-3622

*Marques TA, Thomas L, Ward J, DiMarzio N, Tyack PL (2009) Estimating cetacean population density using fixed passive acoustic sensors: an example with Blainville's beaked whales. J Acoust Soc Am 125:1982-1994

McDonald MA, Fox CG (1999) Passive acoustic methods applied to fin whale population density estimation. J Acoust Soc Am 105:2643-2651

* McDonald MA, Hildebrand JA, Webb SC (1995) Blue and fin whales observed on a seafloor array in the Northeast Pacific. J Acoust Soc Am 98:712-721

*Melcón ML, Cummins AJ, Kerosky SM, Roche LK, Wiggins SM, Hildebrand JA (2012) Blue whales respond to anthropogenic noise. PLOS ONE 7:e32681

* Mellinger DK, Stafford KM, Moore SE, Dziak RP, Matsumoto $H$ (2007) An overview of fixed passive acoustic observation methods for cetaceans. Oceanography 20: $36-45$

*Mizroch SA, Rice DW, Zwiefelhofer D, Waite J, Perryman WL (2009) Distribution and movements of fin whales in the North Pacific Ocean. Mammal Rev 39:193-227

* Moore JE, Barlow J (2011) Bayesian state-space model of fin whale abundance trends from a 1991-2008 time series of line-transect surveys in the California Current. J Appl Ecol 48:1195-1205

* Oleson EM, Širović A, Bayless AR, Hildebrand JA (2014) Synchronous seasonal change in fin whale song in the North Pacific. PLOS ONE 9:e115678

兴 Šrović A, Hildebrand JA (2011) Using passive acoustics to model blue whale habitat off the western Antarctic Peninsula. Deep Sea Res II 58:1719-1728

Šrović A, Hildebrand JA, Wiggins SM (2007) Blue and fin whale call source levels and propagation range in the Southern Ocean. J Acoust Soc Am 122:1208-1215 
Šrović A, Williams LN, Kerosky SM, Wiggins SM, Hildebrand JA (2013) Temporal separation of two fin whale call types across the eastern North Pacific. Mar Biol 160:47-57

Širović A, Oleson EM, Buccowich J, Rice A, Bayless AR (2017) Fin whale song variability in southern California and the Gulf of California. Sci Rep 7:10126

Soule DC, Wilcock WSD (2013) Fin whale tracks recorded by a seismic network on the Juan de Fuca Ridge, northeast Pacific Ocean. J Acoust Soc Am 133:1751-1761

Thompson PO, Findley LT, Vidal O (1992) 20-Hz pulses and other vocalizations of fin whales, Balaenoptera physalus, in the Gulf of California, Mexico. J Acoust Soc Am 92: 3051-3057

Watkins W, Schevill W (1972) Sound source location by arrival-times on a non-rigid three-dimensional hydrophone array. Deep-Sea Res 19:691-706

Watkins WA, Tyack P, Moore KE, Bird JE (1987) The 20-Hz signals of finback whales (Balaenoptera physalus). J Acoust Soc Am 82:1901-1912

Watkins WA, Daher MA, Reppucci GM, George JE, Martin DL, DiMarzio NA, Gannon DP (2000) Seasonality and distribution of whale calls in the North Pacific. Oceanography 13:62-67

Editorial responsibility: Ana Cañadas,

Madrid, Spain
Weirathmueller MJ, Wilcock WSD, Soule DC (2013) Source levels of fin whale $20 \mathrm{~Hz}$ pulses measured in the northeast Pacific Ocean. J Acoust Soc Am 133: 741-749

Welch PD (1967) The use of fast Fourier transform for estimation of power spectra: a method based on time averaging over short, modified periodograms. IEEE Trans Audio Electroacoust 15:70-73

Wiggins SM, Hildebrand JA (2007) High-frequency acoustic recording package (HARP) for broad-band, long-term marine mammal monitoring. In: Proc 2007 Symp Underwat technol and Workshop on scientific use of cables and related technologies, Tokyo, 17-20 April. IEEE, Tokyo, p 551-557

Wiggins SM, Frasier KE, Elizabeth Henderson E, Hildebrand JA (2013) Tracking dolphin whistles using an autonomous acoustic recorder array. J Acoust Soc Am 133:3813-3818

Wilcock WSD (2012) Tracking fin whales in the northeast Pacific Ocean with a seafloor seismic network. J Acoust Soc Am 132:2408-2419

Zimmer W (2011) Passive acoustic monitoring of cetaceans. Cambridge University Press, Cambridge

Submitted: February 13, 2017; Accepted: January 11, 2018 Proofs received from author(s): February 27, 2018 